\title{
Ananlysis of Carbon Emission Reduction and Power Dominance between Single Manufacturer and Single Retailer in Regulatory Cap and Trade System
}

\author{
Liang-jie $\mathrm{Xia}^{1}$ and Hua-wei $\mathrm{Zhi}^{2}$ \\ ${ }^{1}$ School of Business, Tianjin University of Finance and Economy, No. 25, Zhujiang Road, Tianjin 300222, China \\ ${ }^{2}$ School of Management, Tianjin Polytechnic University, No. 399, Binshuixi Road, Tianjin 300387, China \\ Correspondence should be addressed to Hua-wei Zhi; zhihw1983@163.com
}

Received 11 April 2014; Accepted 25 June 2014; Published 11 August 2014

Academic Editor: Xiang Li

Copyright (C) 2014 L.-j. Xia and H.-w. Zhi. This is an open access article distributed under the Creative Commons Attribution License, which permits unrestricted use, distribution, and reproduction in any medium, provided the original work is properly cited.

In the cap and trade system, the paper analyses the Stackelberg game between the power asymmetrical retailer and manufacturer and designs a side-payment self-enforcing contract to resolve some arguments that the existing research overemphasizes spontaneity of participation in side-payment contracts design based on supply chain coordination and does not consider rationality and fairness of allocation of profit increment. Also, the numerical analysis was given. The research shows some important conclusions: in the supply chain, the dominant manufacturer is not able to encourage the retailer to improve its promotion level by increasing its carbon cutting level, but the optimal emission reduction level increases with the dominant retailer's promotion level; the optimal promotion level, emission reduction, and product demand in a retailer leading supply chain are higher than those in a supply chain dominated by manufacturer; with the new side-payment self-enforcing contract, decentralized decision according to individual rationality incurs a collective reason effect in the centralized setting.

\section{Introduction}

With consumer's low-carbon awareness improving, product's carbon emission affects the utility of consumer directly and is becoming one of the most important factors affecting the market demand. All carbon emissions are generated in the process of product manufacturing and delivering to meet the needs of the end consumer, and the consumer's purchase is the fundamental driving force for enterprises' emission cutting [1]. With the influence of awareness of environmental, consumers are willing to pay a higher price for environmentally friendly products [2].

In order to enhance the transparency around the carbon emission of products, carbon labels have become an important common choice of many enterprises to provide carbon related information of their products. And it makes it easy for consumers to compare the carbon footprints of different products and make right purchase decision [3]. At the same time, many international companies take measures to improve their images on carbon emission by publishing annual environmental and social responsibility reports. In a word, the impact of carbon emissions on the demand of product is becoming increasingly important; carbon cutting has become an important issue for enterprises' operational decision making.

Cap and trade system has become an important regulation adopted by many countries to achieve the aim of carbon emission reduction. In this system, emission allowance is necessary for company's production. Company should buy allowance to offset the quota gap from the carbon market if its emission volume is larger than its allowance allocated by government. In contrast, it can sell its surplus quotas to gain profit. So the cap and trade system will significantly affect company's production-related decision-making. However, there are only a few of papers dealing directly with the issue of carbon emissions and operations $[4,5]$.

At the same time, retailers have become the dominant participants in many industries [6], as a matter of fact, they determine the product manufacture and sale of the supply chain [7]. Taking full advantage of their "buyer power," they 
can pass on the operation risk and cost to the manufacturers by some unequal contracts. It is good for the retailers but really hurts the system profit of the supply chain and results in a deviation from Pareto optimality [8]. However, cooperation is also important for the competing enterprises in supply chain. They should cooperate to improve the market demand. For instance, the manufacturer engages in carbon cutting and the retailer focuses on marketing and promoting related to carbon cutting of the product. It is conducive to maximize their profits.

In this paper, considering the impact of carbon emission and promotion on market demand and the regulation of cap and trade on company operation, the game between manufacturer and retailer is analyzed. In the game, the manufacturer decides the carbon emission reduction of per unit of product to maximize its profit and the retailer maximizes its profit by adjusting the promotion levels related to emission cutting. Also, we compare the decision-making of company in supply chain with a dominant manufacturer with that in a supply chain dominated by a retailer. Finally, the paper introduces a new contract to improve the system profit of the supply chain, while the participants make decisions individually. With the new contract, both of the manufacturer and the retailer can gain more profit than before and the supply chain can gain as much system profit as that in centralized decision-making case. Also, the new contract is rational and fair in allocating the profit increment of the supply chain.

The rest of the paper is organized as follows. Section 2 gives the literature review of the supply chain operation and coordination in low-carbon environment. Section 3 sets forth the characteristics of the concerned issue, assumptions, and notations of this paper. In Section 4, we develop game theoretical model of two parties of the supply chain in cap and trade system and analyze the decision-making of the participants in the supply chain dominated by retailer or manufacturer. The centralized decision analysis will be carried out finally. In Section 5, we will show how to coordinate the supply chain with a side-payment self-enforcing contract. In Section 6, the numerical analysis will be shown. Finally, concluding remark and future research are given in Section 7.

\section{Literature Review}

Carbon footprint is the cumulative carbon emissions across the life cycle of product. Integrating the supply chain together to manage the carbon footprint can not only reduce carbon emissions, but also create financial value [9]. The global executives increasingly regard the environment problem including climate change and carbon regulation as one of the top concerns [10]. However, research on supply chain operations under a low-carbon environment is still in its infancy [5]. Existing research can be reviewed from the following three aspects.

Firstly, transportation mode selection is an important topic under carbon regulations. Researches discuss how to cut carbon emission by adjusting the transportation mode of supply chain. Carbon emissions arising from transportation account for a significant proportion of the supply chain carbon footprint [11]. Hoen et al. have made groundbreaking researches in this field. Using case studies, they discovered that in an established network, adjusting transportation model can reduce carbon emissions by $10 \%$ and increased total logistics costs by only $0.7 \%$ [12], but companies should make decision according to specific carbon regulations and practical issues [13].

Secondly, supply chain network design is also an important topic under carbon regulations. Switching logistic model is an effective solution for carbon reducing in established supply chain network. But the network is not always established. Also, companies in different regions or with different ability in carbon cutting are different in marginal cost and marginal profit of carbon cutting. Those differences provide chance for companies to cooperate in emission reduction and optimize carbon emission by redesigning their supply chain network. By this way, they can save logistics cost and enhance carbon cutting level at the same time [14].

Ramudhin et al. [15] introduced a mixed integer mathematical model formulation for green supply chain network design considering carbon trading regulation. They explored solution methodology to evaluate different strategic decisions alternatives and their impact in terms of carbon footprint. Different supply chain network may lead to different carbon intensity in the process of product distribution [16]. Diabat and Simchi-Levi [17] formulated a mixed integer programming model to help companies reveal an optimal strategy to meet their carbon cap and minimize opportunity cost. Supply chain network design would affect the cost of retailers and consumers at the same time, so both the consumers' cost and the retailers' emissions constraints should be considered in supply chain network design [18].

Life cycle assessment (LCA) has been proved as an effective method to reduce the harm to the environment in new products and processes design, but it has been rarely adopted in supply chain management [19]. Considering that, Chaabane et al. [20] integrated LCA into the process of sustainable supply chain designing under carbon trading regulation.

Thirdly, supply chain coordination is another important topic under carbon regulations. Because product carbon footprint is the total carbon emission across its life cycle from raw material used in its manufacturing to the disposal of the finished product, it is difficult for an enterprise to achieve the optimization of carbon footprint by itself, and it is essential for the enterprises in supply chain to cooperate in carbon cutting [21].

In fact, carbon emission can be greatly reduced without significant cost increase by optimizing operation decision and company cooperation across supply chain [4]. For instance, carbon emission in supply chain could be minimized by means of green procurement [22] and order quantity adjustment [23].

Decomposing it into processes of the supply chain is essential for optimizing carbon footprint. Caro et al. [24] introduced a simple but effective model to identify each company's responsibility for carbon emission reduction and provide measures for achieving carbon neutral in supply chain. They found that carbon emission must be allocated based on supply chain system in order to achieve optimal carbon emission level. 
On supply chain coordination, Sunand Cao [25] introduced KMRW reputation model into the repeated games of incomplete information on carbon efficient products between retailers and a single manufacturer. Considering the "capand-trade" regulation, Du et al. [26] investigated companies' decision-making in the emission dependent supply chain in cap and trade system. Based on it, Du et al. [27] considered the emission cap of emission dependent manufacturer allocated by the government as a kind of environmental policy and formally investigated its influence on decision-making within the supply chain as well as distribution fairness in social welfare. Under carbon trading system, Xia et al. [28] took joint carbon emission reduction as a solution to optimize carbon cutting and improve the profit of the supply chain system. Also, Xia et al. [29] introduced side-payment selfenforcing contract to the emission reduction cooperation between the supplier and the manufacturer. Xie and Zhao [30] analyzed the carbon reduction cooperation mechanism in supply chain under the regulation of CDM. With system dynamics, Yang et al. [31] compared the impact of mandatory emission reduction and carbon tax on carbon cutting and the cost of supply chain members.

Xia and $\mathrm{He}$ (2014) analyzed the interactions and decisionmaking on carbon emission reduction and sales promotion in a dyadic supply chain considering consumers' lowcarbon awareness in literature [32]. Although [32] and the present paper study similar games on emission reduction and promotion between single manufacturer and single retailer, they focus on essentially different issues. Firstly in [32], a nonlinear demand function is adopted, while in the present paper, in order to understand whether the results are sensitive to the choice of particular demand structure, a linear demand function is adopted. However, demand characteristics, liner or nonlinear, indeed capture market signals and subsequently affect almost all actions through the channel. This kind of significant difference can also be found in literature [33]. Secondly, the particular difference is that in [32] the regulatory carbon emission policy cap and trade are not yet incorporated as the background scenario for the channel running, which will substantially impacts on the inter-actions choosing as well as channel performance. For example, company's operation decisions are definitely constrained by cap and trade regulation. Furthermore, in [32] consumers' low-carbon awareness is considered but is not incorporated and combined with cap and trade regulatory policy. Compared with [32], the third significant difference is that in present paper we introduce the concept power dominance to research how the shift of power dominance between upstream supplier and downstream retailer influences individual interactions and channel performance in presence of cap and trade regulation and sensitiveness of market low-carbon awareness, which finally impact on both carbon emission reduction and marketing decisions.

\section{Problem Characteristics, Notations, and Assumptions}

In this paper, the supply chain consists of a manufacturer focusing on improving the consumer utility by carbon cutting and a retailer providing promotion for the low-carbon properties of the product.

Some parameters involved are given as follows.

Decision variables:

$v$ : the retailer's promotion level, $0<v<1$;

$e$ : the emission reduction of per unit product, $0 \leq e<$ 1.

Input and output parameters:

$D$ : market demand of product;

$a$ : market volume without considering the impact of emission reduction and sales promotion, $a>0$;

$b$ : the coefficient of promotion level's impact on demand, $b>0$;

$r$ : the coefficient of carbon emission's impact on demand, $r>0$;

$\sigma$ : the emission cap of per unit production, $\sigma>0$;

$p_{c}$ : the price of per unit of carbon allowance, $p_{c}>0$;

$u_{r}$ : the marginal cost of promotion, $u_{r}>0$;

$u_{m}$ : the marginal cost of emission reduction, $u_{m}>0$;

$\rho_{m}$ : manufacturer's profit of per unit product without considering carbon cutting cost, $\rho_{m}>0$;

$\rho_{r}$ : retailer's profit of per unit product without considering promotion cost, $\rho_{r}>0$;

$\Pi_{m}, \Pi_{r}$, and $\Pi$ : the total profit of manufacturer, retailer, and the supply chain system, respectively.

For convenience, this paper is based on the following assumptions. (1) The supply chain provides only one product; (2) the case of out of stock is not considered; (3) both of the retailer and manufacturer earn fixed profits per unit product (without considering the cost of promotion and emission reduction); (4) the retailer has no carbon emission; (5) the bid-ask spreads of carbon emission permit are ignored; (6) the manufacturer's initial emissions of per unit product are 1 ; (6) the relationship between marginal cost of emission reduction and the price of carbon trade satisfies $u_{m}>2 r p_{c}$.

Since the product carbon footprint affects the utility of consumer, carbon emission reduction can enhance product demand. The profit of manufacturing and selling environment-friendly products derives from the demand increment resulting from the improvement of consumer's environmental awareness [2]. In order to enhance product demand, large retail supermarkets often take action to encourage the manufacturers to improve their emission reduction level [34]. For example, Walmart has embraced its responsibility to protect the environment and has paid great attention to reduce emissions. Also, Walmart is profiting from its actions reducing greenhouse gas emissions in its own operations and its supply chain [35]. In addition to providing competitive product quality and price to consumers, carbon cutting and disclosing the information related to carbon emission have become important measures to improve market shares and consumer confidence [7]. 
Considering the price and emission reduction of product, the product demand can be described as $D=D_{0}-k p+$ $b v-r(1-e)$. Price can be shown as $p=c_{r}+c_{m}+$ $\rho_{m}+\rho_{r} \cdot c_{m}$ is the marginal production cost of manufacturer without considering emission reduction. $c_{r}$ is the marginal cost of retailer without considering promotion. Consumers are willing to pay higher price for the environment-friendly products as the improving of their environmental awareness [36]. But the process of public awareness for environment protection enhancing is gradual. Also, the consumers' purchase decisions are constricted by their income. On the current, it is reasonable to suppose that the purpose of companies is to improve market demand by carbon cutting rather than by raising prices. It is similar to the "bonus pack" strategy adopted by companies. So, we assume $\rho_{m}$ and $\rho_{r}$ are constant. Let $a=D_{0}-k\left(c+\rho_{m}+\rho_{r}\right)-r$; the product demand can be expressed as

$$
D=a+b v+r e .
$$

Since the costs of emission reduction $(c(e))$ and promotion $(c(v))$ are convex in $e$ and $v$ respectively, and they can be assumed as $c(e)=u_{m} e^{2} / 2$ and $c(v)=u_{r} v^{2} / 2$, respectively.

Profit function of manufacturer and retailer can be expressed as following, respectively:

$$
\begin{gathered}
\Pi_{m}=\rho_{m}(a+b v+r e)-\frac{u_{m} e^{2}}{2} \\
+(\sigma+e-1) p_{c}(a+b v+r e), \\
\Pi_{r}=\rho_{r}(a+b v+r e)-\frac{u_{r} v^{2}}{2} .
\end{gathered}
$$

\section{Analytical Model}

In a supply chain with a dominant manufacturer or a dominant retailer, the manufacturer and retailer, in pursuit of their own maximal profits, make their optimal decisions on emission reduction and promotion related to carbon cutting, respectively, in Stackelberg game.

4.1. Stackelberg Game between the Retailer and the Dominant Manufacturer. In a supply chain with a dominant manufacturer, the manufacturer makes its optimal decisions on emission cutting. Then the retailer makes its optimal decisions on promotion when sufficient information about emission reduction is acquainted.

The optimal promotion level will be determined according to the retailer's profit-maximizing function which can be given by

$$
\max _{0<v<1} \Pi_{r}=\rho_{r}(a+b v+r e)-\frac{u_{r} v^{2}}{2} .
$$

Since $\partial^{2} \Pi_{r} / \partial v^{2}=-u_{r}<0$, the optimal promotion level can be expressed as

$$
v^{*}=\frac{\rho_{r} b}{u_{r}}
$$

Substituting $v^{*}=\rho_{r} b / u_{r}$ into (2), the optimal carbon emission reduction per unit of production can be gained as

$$
e^{*}=\frac{1}{u_{m}-2 r p_{c}}\left[r \rho_{m}+p_{c} a-r p_{c}(1-\sigma)+\frac{p_{c} b^{2} \rho_{r}}{u_{r}}\right] .
$$

Since $\partial e^{*} / \partial p_{c}>0, \partial e^{*} / \partial u_{m}<0, \partial e^{*} / \partial \rho_{r}>0, \partial e^{*} / \partial \rho_{m}>$ $0, \partial e^{*} / \partial u_{r}<0, \partial v^{*} / \partial \rho_{r}>0$, and $\partial v^{*} / \partial u_{r}<0$, thus we can get Conclusion 1 shown as follows.

Conclusion 1. In the supply chain with a dominant manufacturer, (1) the optimal promotion level $v^{*}$ increases with $\rho_{r}$ and decreases as $u_{r}$ increases, but it has nothing to do with $\rho_{m}, p_{c}$, and $u_{m}$; (2) the optimal emission reduction level $e^{*}$ increases with $\rho_{m}, \rho_{r}$, and $p_{c}$ and decreases as $u_{m}$ and $u_{r}$ increase; (3) the manufacturer is not able to influence the retailer's promotion level by adjusting emission reduction level.

Conclusion 1 shows that the dominant manufacturer is not able to encourage the retailer to improve its promotion level by increasing the volume of emission reduction. The reason is that the retailer can obtain more profit than before without improving promotion if the manufacturer increases emission reduction.

The higher $\rho_{m}$ is, the more profit the manufacturer has to invest in emissions reduction. It results in more demand and more profit in turn. Even it is possible for the manufacturer to sell its surplus quotas to gain more profit by means of emission reduction. The higher $u_{m}$ is, the higher the marginal cost of carbon cutting is, the lower the incentive for the manufacturer to reduce carbon emission is. On the contrary, the higher $p_{c}$ is, the more the relative marginal carbon cutting cost is. So the manufacturer's emission reduction volume increases with $p_{c}$. It is similar to the fact that the optimal emission reduction level increases with $\rho_{r}$ and decreases with $u_{r}$.

4.2. Stackelberg Game between the Manufacturer and the Dominant Retailer. In the supply chain with a dominant retailer, at first, the retailer makes its optimal decisions on promotion level related to emission reduction. Then the manufacturer makes its optimal decisions on emission reduction when sufficient information about promotion level is acquainted.

The optimal carbon cutting level will be determined according to the manufacturer's profit-maximizing function which can be given by

$$
\begin{aligned}
\max _{0 \leq e<1} \Pi_{m}= & \rho_{m}(a+b v+r e)-\frac{u_{m} e^{2}}{2} \\
& +(\sigma+e-1) p_{c}(a+b v+r e) .
\end{aligned}
$$

Since $u_{m}>2 r p_{c}, \Pi_{m}$ is concave in $e$. Let $\partial \Pi_{m} / \partial e=0$; the optimal emission reduction level is gained as

$$
e_{r d}^{*}=\frac{r \rho_{m}+p_{c}(a+b v+r \sigma-r)}{u_{m}-2 r p_{c}} .
$$


Substituting $e_{r d}{ }^{*}$ into (3), let $\partial \Pi_{r} / \partial v=0$; then the retailer's optimal promotion level can be gained as

$$
v_{r d}{ }^{*}=\frac{b \rho_{r}}{u_{r}}\left(1+\frac{r p_{c}}{u_{m}-2 r p_{c}}\right) .
$$

Then the optimal emission reduction is

$$
\begin{aligned}
e_{r d}^{*}= & \frac{1}{u_{r}\left(u_{m}-2 r p_{c}\right)} \\
& \times\left\{u_{r}\left[r \rho_{m}+a p_{c}+r p_{c}(\sigma-1)\right]\right. \\
& \left.+b^{2} \rho_{r} p_{c}\left[1+\frac{r p_{c}}{u_{m}-2 r p_{c}}\right]\right\} .
\end{aligned}
$$

Since $\partial e_{r d}{ }^{*} / \partial v>0, \partial v_{r d}{ }^{*} / \partial \rho_{r}>0, \partial v_{r d}{ }^{*} / \partial \rho_{m}=0$, $\partial v_{r d}{ }^{*} / \partial u_{r}<0, \partial v_{r d}{ }^{*} / \partial u_{m}<0, \partial v_{r d}{ }^{*} / \partial p_{c}>0, \partial e_{r d}{ }^{*} / \partial \rho_{m}>0$, $\partial e_{r d}{ }^{*} / \partial \rho_{r}>0, \partial e_{r d}{ }^{*} / \partial u_{m}<0, \partial e_{r d}{ }^{*} / \partial u_{r}<0, \partial e_{r d}{ }^{*} / \partial p_{c}>0$, $v_{r d}{ }^{*}>v^{*}$, and $e_{r d}{ }^{*}>e^{*}$, thus we can get Conclusion 2 shown as follows.

Conclusion 2. In the supply chain with a dominant retailer, (1) the optimal emission reduction level increases with the retailer's promotion level, $\rho_{m}, \rho_{r}$, and $p_{c}$, and decreases with $u_{m}$ and $u_{r}$; (2) the retailer's optimal promotion level increases with $\rho_{r}$ and $p_{c}$ and decreases with $u_{m}$ and $u_{r}$, but it has nothing to do with $\rho_{m}$; (3) the optimal promotion and emission reduction level in the supply chain dominated by retailer are higher than those in the supply chain dominated by manufacturer.

The optimal emission reduction level increases with the retailer's promotion level. It means that the dominant retailer is able to encourage the manufacturer to improve emission reduction level by improving the promotion level. Since the retailer makes decision firstly. Its decision affects the product demand directly and affects the manufacturer's profit or cost gained by carbon trade. So the retailer's promotion affects the manufacturer's carbon cutting decision. It is an important difference insight compared to the supply chain dominated by manufacturer.

The optimal promotion and emission reduction level in the supply chain dominated by retailer are higher than those in the supply chain dominated by manufacturer. There are two reasons. On the one hand, the retailer is closer to market than the manufacturer. It can obtain market information with lower cost and understand consumer preference more clearly than manufacturer. On the other hand, as above, the manufacturer's emission reduction increases with the promotion level. The retailer can encourage the manufacturer to improve carbon cutting effectively. But the dominant manufacturer is not able to encourage the retailer to improve promotion level. So, the promotion and emission reduction level in the retailer leading supply chain are higher than those in the supply chain dominated by manufacturer.

4.3. Centralized Decision. Centralized decision can bring optimal profit for the supply chain system. But a binding agreement is necessary to encourage the manufacturer and the retailer to agree with centralized decision-making. The optimal carbon cutting and promotion level will be determined according to the system's profit-maximizing function which can be given as

$$
\begin{aligned}
\max _{0 \leq e<1,0<v<1} \Pi(v, e)= & {\left[\rho_{m}+\rho_{r}+(\sigma+e-1) p_{c}\right] } \\
& \times(a+b v+r e)-\frac{1}{2} u_{m} e^{2}-\frac{1}{2} u_{r} v^{2}
\end{aligned}
$$

If $-u_{r}\left(2 r p_{c}-u_{m}\right)-b^{2} p_{c}{ }^{2} \geq 0$, the optimal carbon reduction and promotion level of the centralized decision supply chain can be expressed as

$$
\begin{aligned}
e^{* *} & =\frac{a u_{r} p_{c}+\left(b^{2} p_{c}+r u_{r}\right)\left[\rho_{m}+\rho_{r}+(\sigma-1) p_{c}\right]}{u_{m} u_{r}-2 r u_{r} p_{c}-b^{2} p_{c}^{2}}, \\
v^{* *} & =\frac{b\left(u_{m}-r p_{c}\right)\left[\rho_{m}+\rho_{r}+(\sigma-1) p_{c}\right]+a b p_{c}^{2}}{u_{m} u_{r}-2 r u_{r} p_{c}-b^{2} p_{c}^{2}} .
\end{aligned}
$$

\section{Supply Chain Coordination Based on Side-Payment Contract Design}

The decision $\left(v^{* *}, e^{* *}\right)$ is the optimal decision of the centralized decision supply chain. It achieves the system' Pareto equilibrium point without considering the cost of resource allocation between the manufacturer and the retailer. It is also the benchmark of maximizing the outputs of the supply chain system.

Obviously, because of double marginal effect, it is impossible to achieve the optimal profit point in Stackelberg game without effective contract. In a centralized decision supply chain, the profit of the system can be maximized, and it is possible for the manufacturer and the retailer to gain more profit than in decentralized decision model. It provides impetus for the manufacturer and the retailer to cooperate. At the same time, participation constraint and incentive compatible constraint are two essential constraints for the manufacturer and the retailer to agree with centralized decision-making. The distribution of profit increment must be fair and reasonable from the perspective of both manufacturer and retailer.

Assume that the supply chain is dominated by the manufacturer. In the following section, the paper will analyze how to achieve Pareto Optimality with a side-payment selfexecuting contracts (SSEC) [37]. The new contract changes the payment function of both sides in the game and makes the supply chain system achieve the same optimal profit as in centralized decision-making model when the manufacturer and the retailer make decision according to individual rationality. At the same time, the profits of manufacturer and retailer satisfy the participation constraint and the incentive compatible constraint, and both of the players agree the deal is fair.

The side-payment self-executing contracts can be designed as $\widetilde{T}(v, e)=T(v, e)+g$. In order to conveniently research, $T(v, e)$ can be assumed as the linear function about $v$ and $e$; that is, $T(v, e)=x v+y e$. $x$ and $y$ are nonzero constants. The parameter $g$ is constant. In this case, the 
profit-maximizing functions of the manufacturer and the retailer can be expressed, respectively, as follows (the actual direction of the side-payment is determined according to the sign of $\widetilde{T}(v, e))$ :

$$
\begin{aligned}
\max _{0 \leq e<1} \Pi_{m}^{\prime}= & \Pi_{m}-\widetilde{T}(v, e) \\
= & {\left[\rho_{m}+(\sigma+e-1) p_{c}\right](a+b v+r e) } \\
& -\frac{1}{2} u_{m} e^{2}-T(v, e)-g, \\
\max _{0 \leq v<1}^{\prime}= & \Pi_{r}+\widetilde{T}(v, e) \\
= & \rho_{r}(a+b v+r e)-\frac{1}{2} u_{r} v^{2} \\
& +T(v, e)+g .
\end{aligned}
$$

Since all of $\Pi_{m}(v, e), \Pi_{r}(v, e)$, and $\widetilde{T}(v, e)$ are concave in $v$ and $e$, both of $\Pi_{m}^{\prime}(v, e)$ and $\Pi_{r}^{\prime}(v, e)$ are concave in $v$ and $e$. In this case, the manufacturer plays Stackelberg game with the retailer and decides its emission reduction to maximize its profit firstly. Then, the retailer makes decision about the promotion level to maximize its profit. The equilibrium of the game could be gained by backward induction as follows:

$$
\begin{gathered}
v^{\prime}=\frac{\rho_{r} b+x}{u_{r}}, \\
e^{\prime}=\frac{1}{u_{m}-2 r p_{c}} \\
\quad \times\left\{p_{c}\left(a+b \frac{\rho_{r} b+x}{u_{r}}\right)+r\left[\rho_{m}+(\sigma-1) p_{c}\right]-y\right\} .
\end{gathered}
$$

Then, the requirement of the side-payment self-executing contracts can be expressed as follows.

5.1. Incentive Compatible Constraint. The game equilibrium in case of side-payment self-executing contracts is the same as that in case of centralized decision-making; that is, $\left(v^{\prime}, e^{\prime}\right)=$ $\left(v^{* *}, e^{* *}\right)$

Under this constraint, since the optimal decisions in the two cases are the same, the profit of the system in the two cases is the same and the supply chain system is able to achieve Pareto Optimality.

5.2. Participation Constraint. Both of the manufacturer and the retailer are able to gain more profit in case of sidepayment self-executing contracts implemented not less than that before this contract is adopted; that is, $\Pi_{m}^{\prime} \geq \Pi_{m}{ }^{*}$, $\Pi_{r}^{\prime} \geq \Pi_{r}^{*}$.
The side-payment function is determined once $x, y$, and $g$ are determined. According to the incentive compatible constraint, $x$ and $y$ can be given as follow:

$$
\begin{aligned}
& x=-\rho_{r} b+u_{r}(\left(b p_{c}^{2}(r \sigma-r+a)\right. \\
&\left.+b\left(u_{m}-2 r p_{c}\right)\left[\rho_{m}+\rho_{r}+(\sigma-1) p_{c}\right]\right) \\
& \times\left.\left(u_{m} u_{r}-2 r p_{c} u_{r}-b^{2} p_{c}^{2}\right)^{-1}\right), \\
& y=r \rho_{m} .
\end{aligned}
$$

Then, the side-payment function can be expressed as

$$
\begin{aligned}
\widetilde{T}(v, e)=- & \left(\left(b u_{r} p_{c}(\sigma-1)\left(u_{m}-r p_{c}\right)+b p_{c}^{2}\left(a u_{r}-b^{2} \rho_{r}\right)\right.\right. \\
& \left.+b u_{r}\left(u_{m}-2 r p_{c}\right)\left(2 \rho_{r}+\rho_{m}\right)\right) \\
& \left.\times\left(u_{m} u_{r}-2 r p_{c} u_{r}-b^{2} p_{c}{ }^{2}\right)^{-1}\right) v \\
& -r\left[(\sigma-1) p_{c}+\rho_{m}\right] e+g .
\end{aligned}
$$

In the following section, we discuss how the value of $g$ can be determined according to the participation constraint.

As pointed out in [32], Nash bargainingtheory is often used to resolve the problem of profit allocating in perfect information static game. In fact, Nash bargaining theory is fitful in the case of cooperative game. When Nash bargaining is adopted, a binding agreementis necessary for the dominantplayer would not prefer to cooperative game. So Nash bargaining solution is not easy to achieve. But in real market, transaction is frequently between the manufacturer and the retailer. It is similar to multi-period bargaining game. So we can adopt Rubinstein bargaining game to simulate the process of profit allocation.

Ruhinstein [38] has proved thata unique sub-game refining Nash equilibrium is existed as $\left(\delta_{r}{ }^{*}, \delta_{m}{ }^{*}\right)=\left(\left(1-\theta_{r}\right) /(1-\right.$ $\left.\left.\theta_{r} \theta_{m}\right),\left(\theta_{r}-\theta_{r} \theta_{m}\right) /\left(1-\theta_{r} \theta_{m}\right)\right)$ in an indefinite duration alternating offers game. In which $\theta_{r}$ and $\theta_{m}$ is the discount factors of retailer and manufacturer respectively, $\delta_{r}$ and $\delta_{m}$ denote the share of profit increment of retailer and manufacturer in total profit increment because of cooperation respectively $\left(\delta_{r}+\delta_{m}=1\right)$. And the larger $\delta$ is, the more patient the player is, the greater impact it has on the game and less lost it will suffered because of time delay. In this paper,

$$
\begin{aligned}
\Delta \Pi_{m} & =\Pi_{m}^{\prime}-\Pi_{m}^{*} \\
& =\Pi_{m}\left(v^{\prime}, e^{\prime}\right)-T\left(v^{\prime}, e^{\prime}\right)-g-\Pi_{m}\left(v^{*}, e^{*}\right) \\
& =\delta_{m} \Delta \Pi, \\
\Delta \Pi_{r} & =\Pi_{r}^{\prime}-\Pi_{r}^{*} \\
& =\Pi_{r}\left(v^{\prime}, e^{\prime}\right)+T\left(v^{\prime}, e^{\prime}\right)+g-\Pi_{r}\left(v^{*}, e^{*}\right) \\
& =\delta_{r} \Delta \Pi, \\
\Delta \Pi & =\Delta \Pi_{m}+\Delta \Pi_{r} .
\end{aligned}
$$


TABLE 1: The value of some parameters.

\begin{tabular}{|c|c|c|c|c|c|}
\hline & $\rho_{m}$ & $\rho_{r}$ & $u_{m}$ & $u_{r}$ & $p_{C}$ \\
\hline Figure 1 & $2 \leq \rho_{m} \leq 5$ & 10 & 650 & 500 & 4 \\
\hline Figure 2 & 4 & $6 \leq \rho_{r} \leq 10$ & 650 & 500 & 4 \\
\hline Figure 3 & 4 & 10 & $650 \leq u_{m} \leq 800$ & 500 & 4 \\
\hline Figure 4 & 4 & 10 & 650 & $400 \leq u_{r} \leq 600$ & 4 \\
\hline Figure 5 & 4 & 10 & 800 & 600 & $3 \leq p_{c} \leq 5$ \\
\hline
\end{tabular}

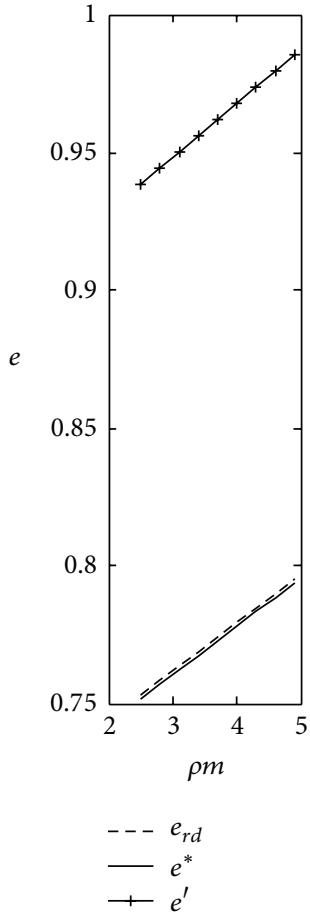

(a) The impact of $\rho_{m}$ on $e$

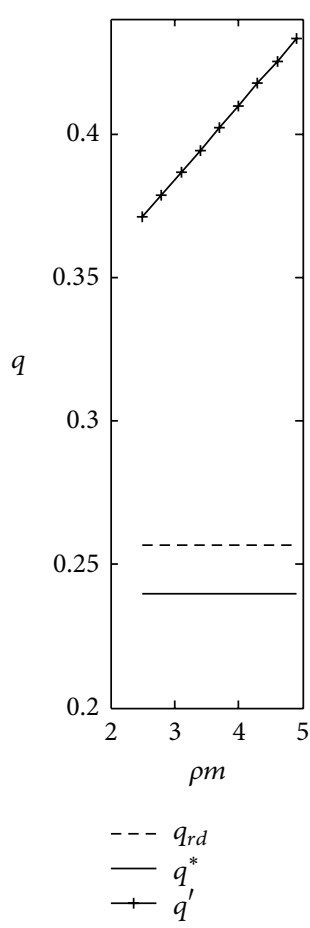

(b) The impact of $\rho_{m}$ on $q$

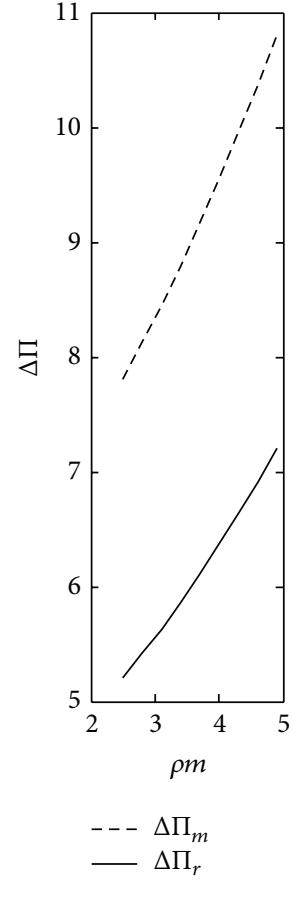

(c) The impact of $\rho_{m}$ on $\Delta \Pi$

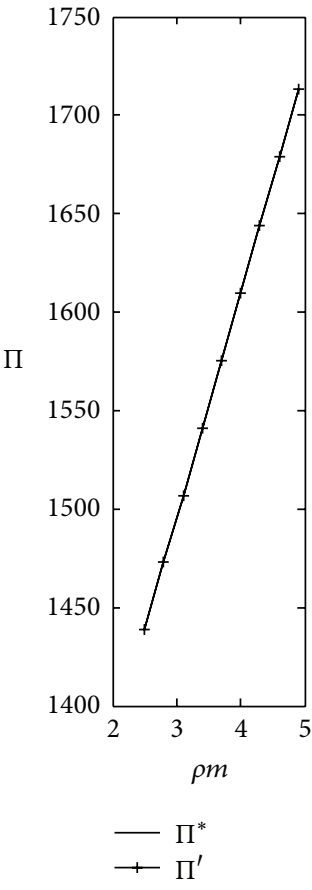

(d) The impact of $\rho_{m}$ on $\Pi$

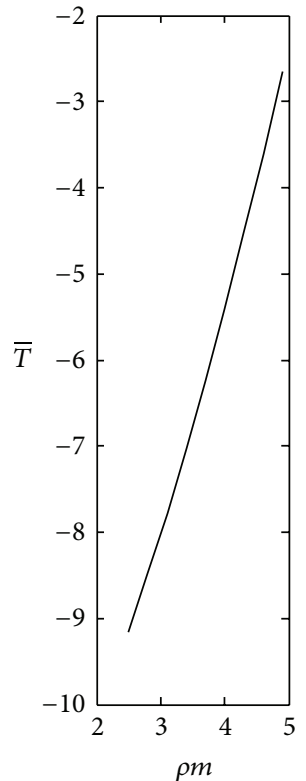

(e) The impact of $\rho_{m}$ on side-payment

Figure 1: The impact of $\rho_{m}$ on decision variables and profits.

Based on the above three equations, the value of $g$ can be determined by

$$
\begin{aligned}
g= & \delta_{r} \\
& {\left[\Pi_{m}\left(v^{\prime}, e^{\prime}\right)-T\left(v^{\prime}, e^{\prime}\right)-\Pi_{m}\left(v^{*}, e^{*}\right)\right] } \\
& -\delta_{m}\left[\Pi_{r}\left(v^{\prime}, e^{\prime}\right)+T\left(v^{\prime}, e^{\prime}\right)-\Pi_{r}\left(v^{*}, e^{*}\right)\right] .
\end{aligned}
$$

According to the result of game equilibrium above and (18), the value of $g$ can be determined. Thus, the side-payment function of the new contract, $\widetilde{T}(q, e)=x q^{2}+y e^{2}+g$, can be identified.

\section{Numerical Analysis}

In the following section, assuming the manufacturer is the dominator, we analyze the impact of $u_{m}, u_{r}, p_{c}, \rho_{r}$, and $\rho_{m}$ on the decision and profit of manufacturer and retailer and the profit of the supply chain system. Also, we illustrate the application of the side-payment self-executing contract.
The similar analysis can be carried out in the supply chain dominated by retailer.

To ensure the existence of optimum conditions in all kinds of game, the related parameters are set as follows.

Let $a=100, b=12, \sigma=0.8, r=10, \delta_{m}=0.6$, and $\delta_{r}=0.4$. The values of $u_{m}, u_{r}, p_{c}, \rho_{r}$ and $\rho_{m}$ are shown as Table 1.

The output of numerical analysis, expressed from Figures 1 to 5 , verifies Conclusions 1 and 2. At the same time, some important conclusions are gained as follows.

(1) In the case of implementing the side-payment selfexecuting contract, the dominant manufacturer's optimal emission reduction level increases with $\rho_{m}, \rho_{r}$, and $p_{c}$ (shown as Figures 1(a), 2(a), and 5(a), resp.), but it decreases with increasing $u_{m}$ and $u_{r} p_{c}$ (shown as Figures 3(a) and 4(a), resp.). It is the same as the discipline before the new contract was implemented. In the supply chain dominated by manufacturer, the main purpose of the contract is to encourage the retailer to improve the promotion level. It does not affect 


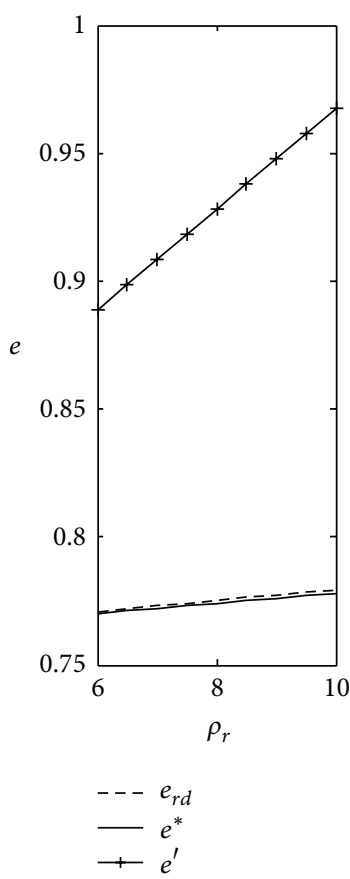

(a) The impact of $\rho_{r}$ on $e$

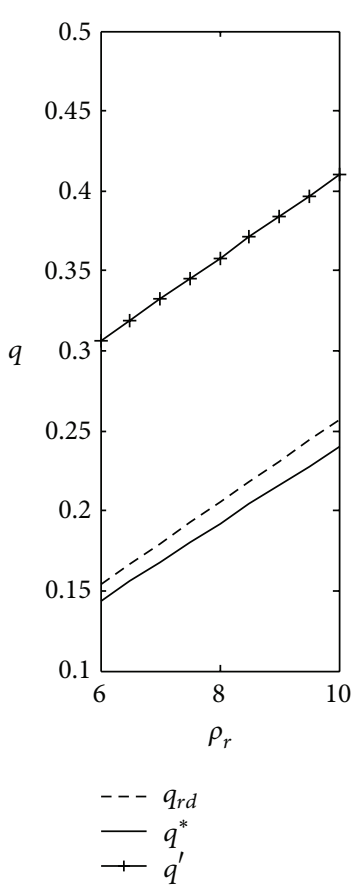

(b) The impact of $\rho_{r}$ on $q$

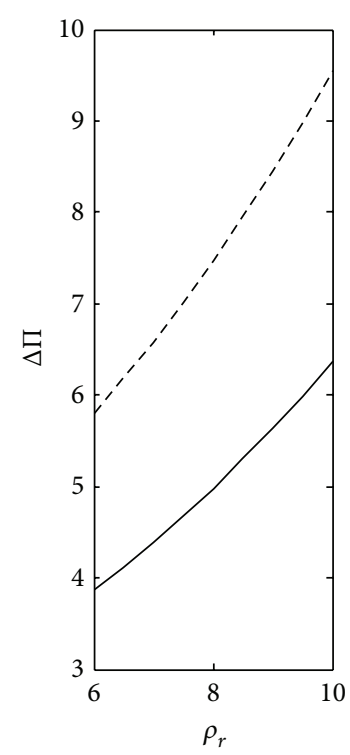

$--\Delta \Pi_{m}$

$-\Delta \Pi_{r}$

(c) The impact of $\rho_{r}$ on $\Delta \Pi$

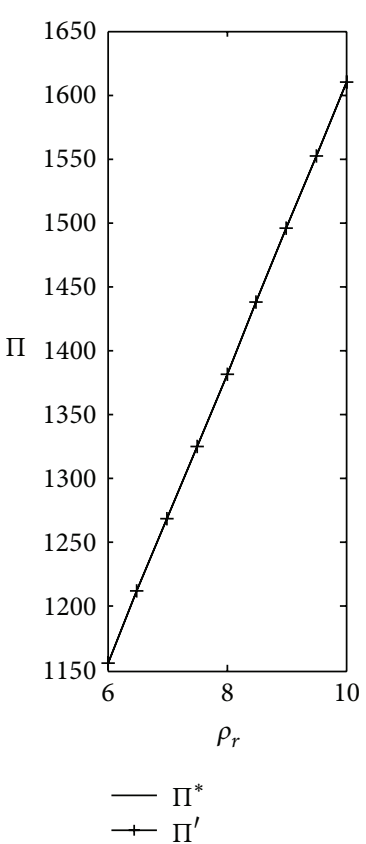

(d) The impact of $\rho_{r}$ on $\Pi$

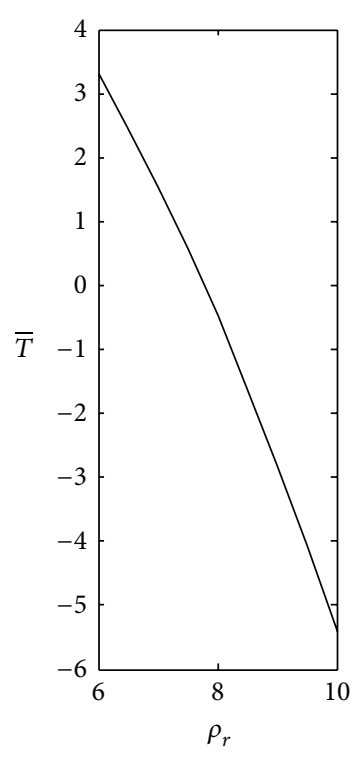

(e) The impact of $\rho_{r}$ on sidepayment

FIgURE 2: The impact of $\rho_{r}$ on decision variables and profits.

the impact of $\rho_{m}, \rho_{r}, p_{c}, u_{m}$, and $u_{r}$ on the manufacturer's decision-making.

(2) With the side-payment self-executing contract implemented, the optimal promotion level of the retailer, $v^{\prime}$, in the supply chain dominated by the manufacturer, increases with the increasing $\rho_{r}, \rho_{m}$, and $p_{c}$ (shown as Figures 1(b), 2(b), and 5(b), resp.), but it is decreases with the increasing $u_{r}$ and $u_{m}$ (shown as Figures 4(b) and 3(b), resp.).

Similar to the analysis in Section 4.1, $v^{\prime}$ increases with $\rho_{r}$ and decreases with $u_{r}$ after the new contract is implemented.
Before implementing the new contract, since the retailer can obtain more profit than the case without improving promotion if the manufacturer increases emission reduction, the dominant manufacturer is not able to encourage the retailer to improve its promotion level by increasing emission reduction. In this case, $v^{\prime}$ has nothing to do with $\rho_{m}$ and $u_{m}$.

In the side-payment self-executing contract, $T(v, e)=$ $x v+y e$ makes the profit increment associate with emission reduction and promotion level, and $g$ makes the allocation of profit increment associate with the participant's discount 


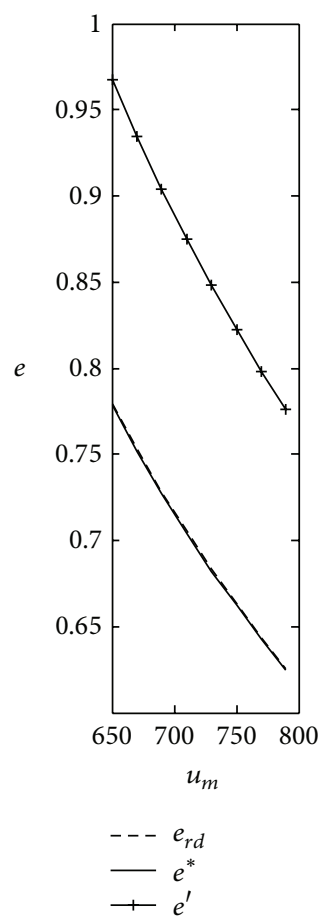

(a) The impact of $u_{m}$ on $e$

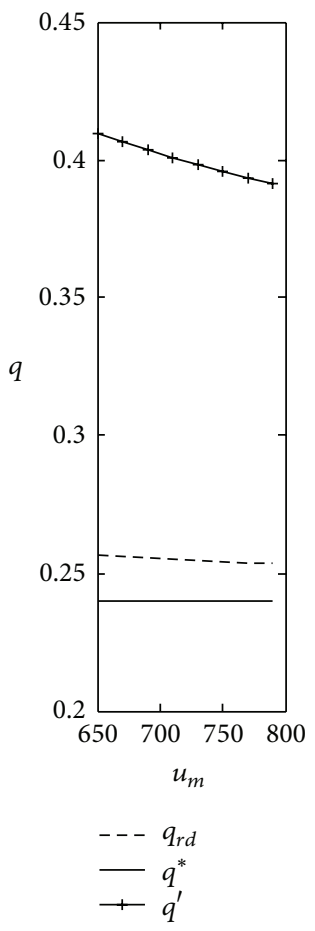

(b) The impact of $u_{m}$ on $q$

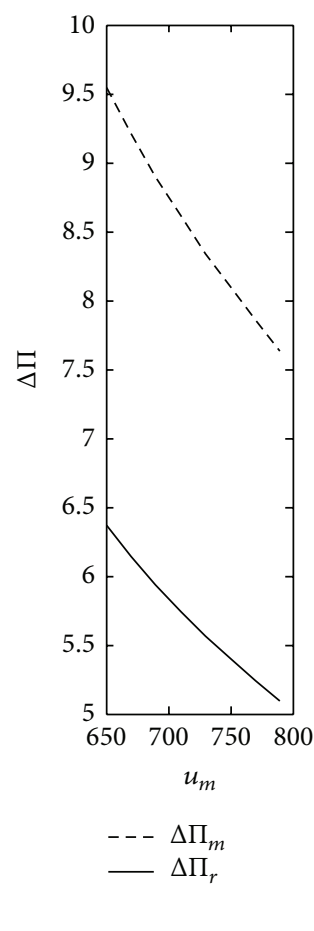

(c) The impact of $u_{m}$ on $\Delta \Pi$
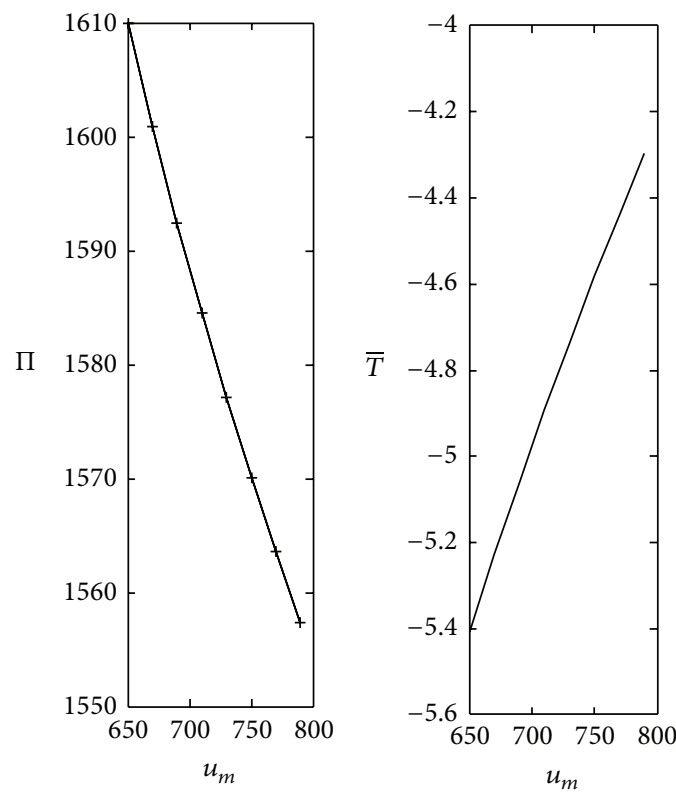

$-\Pi^{*}$

$+\Pi^{\prime}$

(d) The impact of $u_{m}$ on $\Pi$

(e) The impact of $u_{m}$ on side-payment

FIGURE 3: The impact of $u_{m}$ on decision variables and profits.
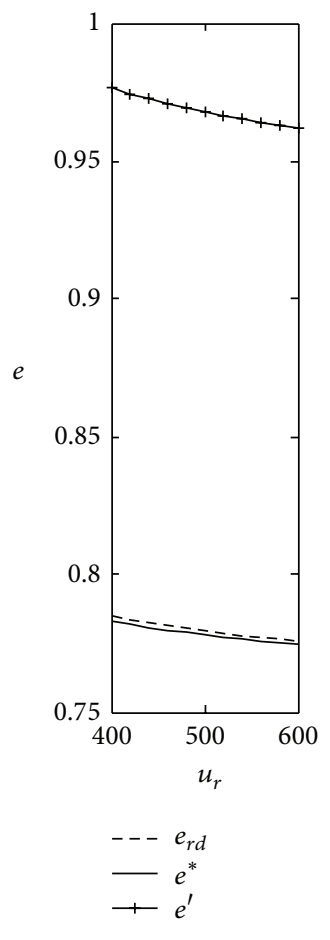

(a) The impact of $u_{r}$ on $e$
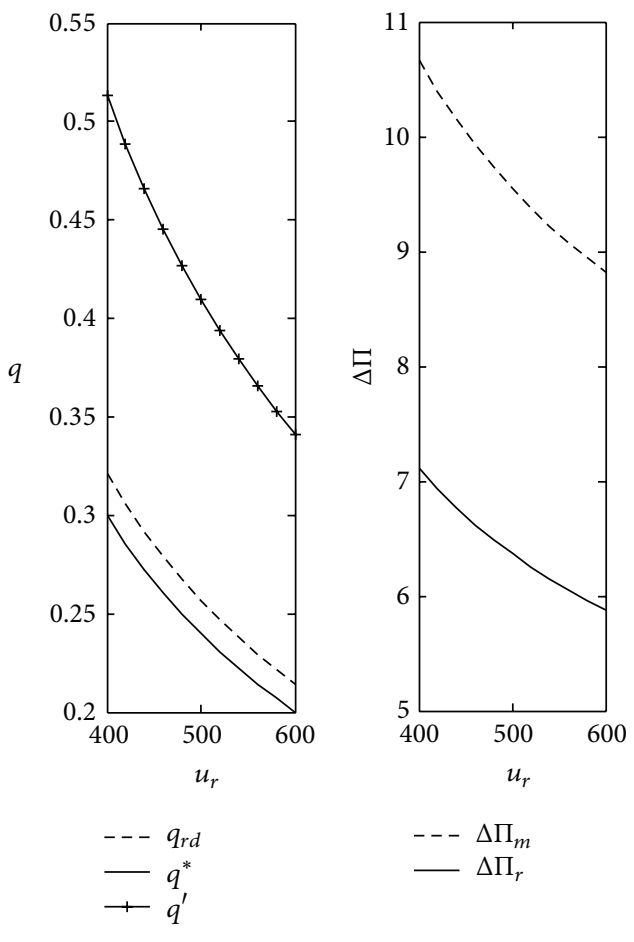

(b) The impact of $u_{r}$ on $q$

(c) The impact of $u_{r}$ on
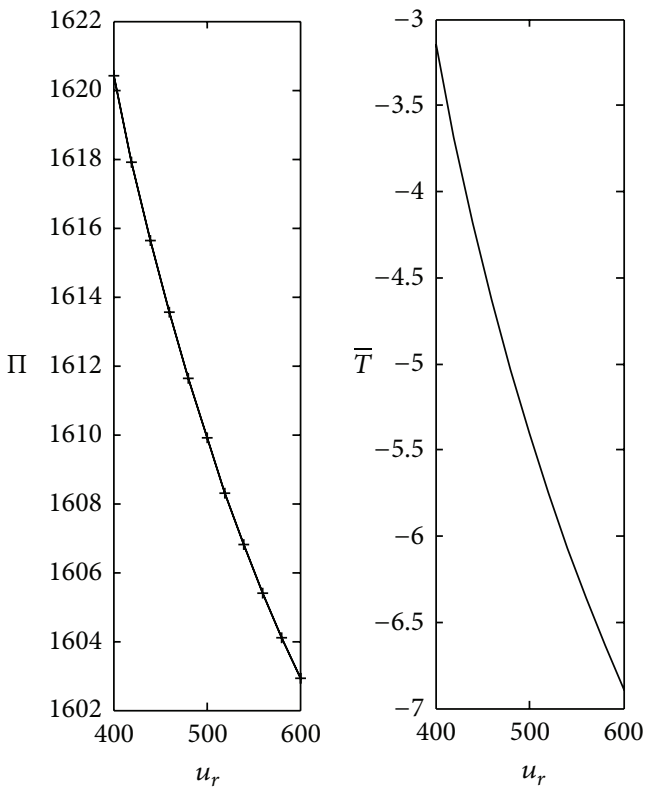

$--\Delta \Pi_{m}$
$-\Delta \Pi_{r}$ $\Delta \Pi$ (e) The impact of $u_{r}$ on side-payment

Figure 4: The impact of $u_{r}$ on decision variables and profits. 


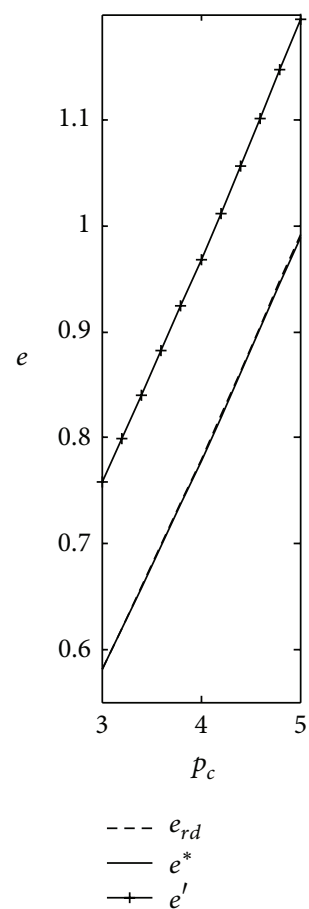

(a) The impact of $p_{c}$ on $e$

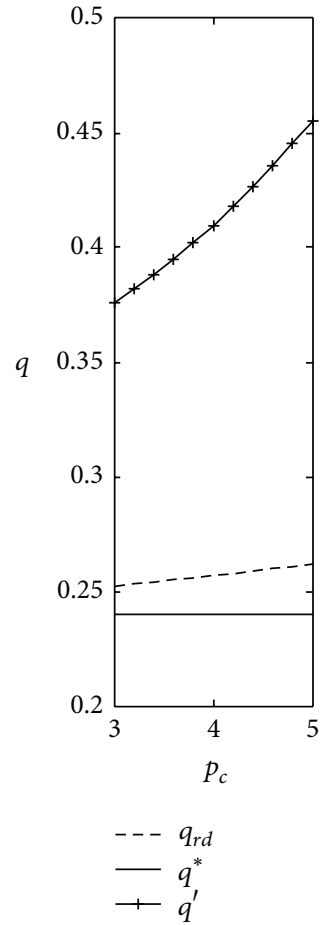

(b) The impact of $p_{c}$ on $q$

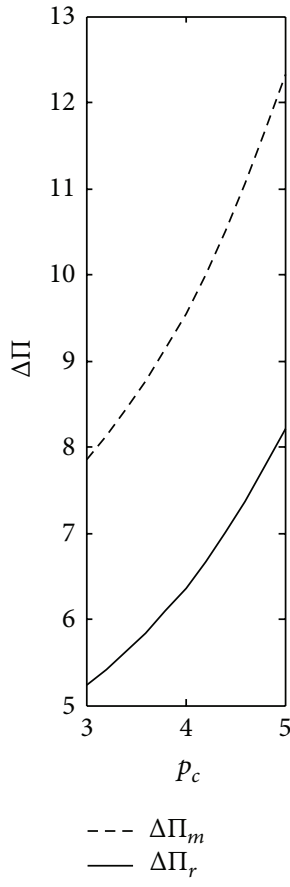

(c) The impact of $p_{c}$ on $\Delta \Pi$

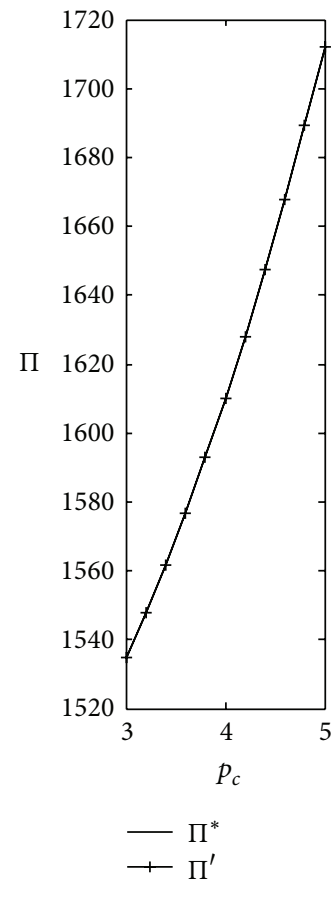

(d) The impact of $p_{c}$ on $\Pi$

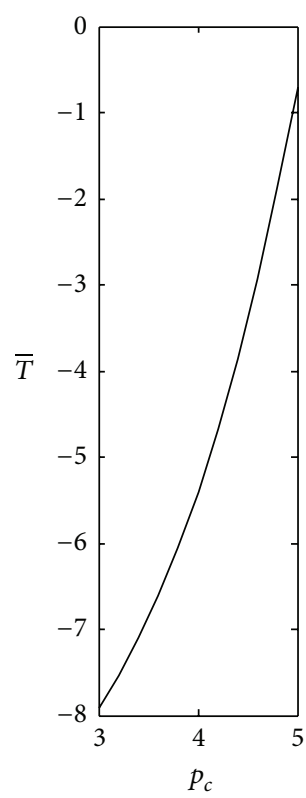

(e) The impact of $p_{c}$ on side-payment

FIgURE 5: The impact of $p_{c}$ on decision variables and profits.

factors. Because of those, the allocation of incremental profit is fair, and the retailer's promotion level increases with emission reduction level. So the parameters influencing the manufacturer's decision-making affect the retailer's decisionmaking too.

(3) With the side-payment self-executing contract, the profit of supply chain system when the manufacturer and retailer make decision individually is equal to that in centralized decision-making case; that is, $\Pi^{\prime}=\Pi^{* *}$ ( shown as Figures 1(d), 2(d), 3(d), 4(d), and 5(d), resp.). And both the promotion level and emission reduction level are higher than before; that is, $e^{\prime}>e_{r d}{ }^{*}>e^{*}$ (shown as Figures 1(a), 2(a), 3(a), 4(a), and 5(a)) and $v^{\prime}>v_{r d}{ }^{*}>v^{*}$ (shown as Figures 1(b), 2(b), 3(b), 4(b), and 5(b)).

Since the side-payment self-executing contract satisfies both the participation constraint and the incentive compatible constraint, the incremental profit can be allocated fairly, and the contradiction between individuals and system is resolved when the participants make decision individually. Thus, $\Pi^{\prime}=\Pi^{* *}$. At the same time, the manufacturer is willing to improve emission reduction level and so is the retailer. Combined with the previous analysis, $e_{r d}{ }^{*}>e^{*}$, and $v_{r d}{ }^{*}>v^{*}$, we can gain the conclusion $e^{\prime}>e_{r d}{ }^{*}>e^{*}$ and $v^{\prime}>v_{r d}{ }^{*}>v^{*}$.

(4) With the side-payment self-executing contract, all the profit of the supply chain system, manufacturer, retailer, and the profit increment of the system increase with the increasing $\rho_{m}, \rho_{r}$ and $p_{c}$ (shown as Figures 1(c), 2(c), and 5(c), resp.), and decreases with the increasing $u_{m}$ and $u_{r}$ (shown as Figures 3(c) and 4(c), resp.).

According to the previous analysis, it is obvious that $\Pi^{\prime}$ increases with $\rho_{m}, \rho_{r}$, and $p_{c}$ and decreases with $u_{m}$ and $u_{r}$. In case that the new contract is executed, either of the manufacturer and the retailer improves its decision value which can improve the profit of the supply chain system and the profit increment will be allocated fairly between the participants. Thus, both of the participants' profits are improved, the increments $\Delta \Pi_{m}$ and $\Delta \Pi_{r}$ increase with $\rho_{m}, \rho_{r}$, and $p_{c}$ and decrease with $u_{m}$ and $u_{r}$.

(5) The sign of the side-payment function $(\widetilde{T})$ is uncertain, shown as Figures 1(e), 2(e), 3(e), 4(e), and 5(e).

Since the side-payment function $(\widetilde{T})$ is designed to encourage the participants to improve emission reduction and promotion level and to balance the allocation of profit increment, its sign is determined by the value of $T(v, e)=$ $x v+y e$ and $g$.

\section{Conclusions}

The paper studies the Stackelberg game between a retailer and a manufacturer considering the cap and trade system and analyzes the impact of $\rho_{r}, \rho_{m}, p_{c}, u_{m}$, and $u_{r}$ on the participants' decision-making. Some conclusions are gained: the dominant manufacturer is not able to encourage the retailer to improve its promotion level by increasing emission 
reduction, but the dominant retailer is able to encourage the manufacturer to increase its emission reduction by improving promotion level; the optimal emission reduction and promotion level in the retailer leading supply chain are higher than those in the supply chain dominated by manufacturer. Further, using the manufacturer leading supply chain for example, the paper designs a side-payment self-enforcing contract to maximize the system profit of supply chain and to make the optimal system profit in case of decentralized decision-making equal to that in case of centralized decisionmaking. Finally, a numerical analysis is given.

The paper considers the impact of carbon cutting and promotion related to carbon cutting on the product demand under the cap and trade system. The side-payment selfenforcing contract can resolve the arguments that the existing research overemphasizes on spontaneity of participation in side-payment contracts design based on supply chain coordination and does not consider rationality and fairness of allocation of profit increment. It is helpful for the company operation under low-carbon environment. The paper is based on a two-echelon supply chain with deterministic product demand. The research on supply chain coordination in case of supply chain network with stochastic product demand considering carbon regulations is the further research direction.

\section{Conflict of Interests}

The authors declare that there is no conflict of interests regarding the publication of this paper.

\section{Acknowledgments}

The authors would like to express their sincere thanks to the anonymous referees and editors for their time and patience devoted to the review of this paper. This work is partially supported by NSFC Grants (nos. 71202086 and 71302115), the Scientific Research Development Fund of Tianjin University of Finance and Economy (no. Q130204), and the Training Program for Innovation Teams of Universities in Tianjin (no. TD12-5051).

\section{References}

[1] Carbon Trust, The Carbon Emissions Generated in All That We Consume, Carbon Trust, London, UK, 2006.

[2] Z. Liu, T. D. Anderson, and J. M. Cruz, "Consumer environmental awareness and competition in two-stage supply chains," European Journal of Operational Research, vol. 218, no. 3, pp. 602-613, 2012.

[3] M. A. Cohen and M. P. Vandenbergh, "The potential role of carbon labeling in a green economy," Energy Economics, vol. 34, no. 1, pp. S53-S63, 2012.

[4] S. Benjaafar, Y. Li, and M. Daskin, "Carbon footprint and the management of supply chains: insights from simple models," IEEE Transactions on Automation Science and Engineering, vol. 10, no. 1, pp. 99-116, 2013.

[5] J. Chen, "Study on supply chain management in low-carbon era," Journal of Systems \& Management, vol. 21, no. 6, pp. 721729, 2012
[6] R. Inderst and C. Wey, "Buyer power and supplier incentives," European Economic Review, vol. 51, no. 3, pp. 647-667, 2007.

[7] T. Geylani, A. J. Dukes, and K. Srinivasan, "Strategic manufacturer response to a dominant retailer," Marketing Science, vol. 26, no. 2, pp. 164-178, 2007.

[8] J. Han, D. Zhao, and J. Qin, "Evolutionary game analysis of bertrand duopoly's behavior to their upstream suppliers," Journal of Management Sciences, vol. 22, no. 2, pp. 57-63, 2009.

[9] E. L. Plambeck, "Reducing greenhouse gas emissions through operations and supply chain management," Energy Economics, vol. 34, no. 1, pp. S64-S74, 2012.

[10] McKinsey, "How companies think about climate change: a McKinsey global survey," The McKinsey Quarterly, 2008.

[11] E. Masanet, K. J. Kramer, G. Homan et al., "Assessment of household carbon footprint reduction potentials," Tech. Rep., California Energy Commission, California, Calif, USA, 2008.

[12] K. M. R. Hoen, T. Tan, C. J. Fransoo et al., "Switching transport modes to meet voluntary carbon emission targets," Transportation Science, pp. 1-17, 2013.

[13] K. M. R. Hoen, T. Tan, J. C. Fransoo, and G. J. van Houtum, "Effect of carbon emission regulations on transport mode selection under stochastic demand," Flexible Services and Manufacturing Journal, vol. 26, no. 1-2, pp. 170-195, 2014.

[14] S. Elhedhli and R. Merrick, "Green supply chain network design to reduce carbon emissions," Transportation Research D: Transport and Environment, vol. 17, no. 5, pp. 370-379, 2012.

[15] A. Ramudhin, A. Chaabane, M. Kharoune, and M. Paquet, "Carbon market sensitive green supply chain network design," in Proceedings of the IEEE International Conference on Industrial Engineering and Engineering Management (IEEM '08), pp. 10931097, Singapore, December 2008.

[16] S. Cholette and K. Venkat, "The energy and carbon intensity of wine distribution: a study of logistical options for delivering wine to consumers," Journal of Cleaner Production, vol. 17, no. 16, pp. 1401-1413, 2009.

[17] A. Diabat and D. Simchi-Levi, "A carbon-capped supply chain network problem," in Proceedings of the IEEE International Conference on Industrial Engineering and Engineering Management (IEEM '09), pp. 523-527, December 2009.

[18] G. P. Cachon, "Supply chain design and the cost of greenhouse gas emissions," Working Paper, University of Pennsylvania, 2011.

[19] S. Seuring and M. Müller, "Core issues in sustainable supply chain management: a Delphi study," Business Strategy and the Environment, vol. 17, no. 8, pp. 455-466, 2008.

[20] A. Chaabane, A. Ramudhin, and M. Paquet, "Design of sustainable supply chains under the emission trading scheme," International Journal of Production Economics, vol. 135, no. 1, pp. 37-49, 2012.

[21] K. H. Lee, "Integrating carbon footprint into supply chain management: the case of Hyundai Motor Company (HMC) in the automobile industry," Journal of Cleaner Production, vol. 19, no. 11, pp. 1216-1223, 2011.

[22] T. Abdallah, A. Diabat, and D. Simchi-Levi, "A carbon sensitive supply chain network problem with green procurement," in Proceedings of the 40th International Conference on Computers and Industrial Engineering (CIE '10), pp. 1-6, Awaji, Japan, July 2010.

[23] X. Chen, S. Benjaafar, and A. Elomri, "The carbon-constrained EOQ," Operations Research Letters, vol. 41, no. 2, pp. 172-179, 2013. 
[24] F. Caro, C. Corbett, T. Tan, and R. Zuidwijk, "Carbon-optimal and carbon-neutral supply chains," Working Paper, Anderson Graduate School of Management-Decisions, Operations, and Technology Management, UC Los Angeles, 2011.

[25] F. Sun and J. Cao, "Research on cooperation and incentive mechanism in low-carbon supply chain based on KMRW model," Research on Financial and Economic Issues, no. 12, pp. 45-49, 2011.

[26] S. Du, F. Ma, Z. Fu et al., "Game-theoretic analysis for an emission-dependent supply chain in a "cap-and- trade" system," Annals of Operations Research, pp. 1-15, 2011.

[27] S. Du, L. Zhu, L. Liang, and F. Ma, "Emission-dependent supply chain and environment-policy-making in the "cap-and-trade" system," Energy Policy, vol. 57, pp. 61-67, 2013.

[28] L. Xia, D. Zhao, and Y. Li, "Game on jointly emission reduction based on transfer payment contract between the supplier and the manufacturer," Systems Engineering, vol. 31, no. 8, pp. 39-46, 2013.

[29] L. Xia, D. Zhao, L. He et al., "Game on carbon emission reduction and coordination based on side-payment self-enforcing contract between supplier and manufacturer," Chinese Journal of Management, vol. 11, no. 5, pp. 750-757, 2004.

[30] X. Xie and D. Zhao, "Research on cooperation strategy of enterprises' carbon emission reduction in low carbon supply chain," Journal of Management Science, vol. 26, no. 3, pp. 108119, 2013.

[31] J. Yang, J. Li, and W. Lu, "The impact of emission policies on supply chain based on system dynamics," Industrial Engineering and Management, vol. 17, no. 4, pp. 21-30, 2012.

[32] L. Xia and L. He, "Game theoretic analysis of carbon emission reduction and sales promotion in dyadic supply chain in presence of consumers' low-carbon awareness," Discrete Dynamics in Nature and Society, vol. 2014, Article ID 837376, 13 pages, 2014.

[33] C. D. Ozgun, Y. Chen, and J. Li, "Channel coordination under fairness concerns and nonlinear demand," European Journal of Operational Research, vol. 207, no. 3, pp. 1321-1326, 2010.

[34] S. Jing, "The impact of green marketing on consumer psychology and behavior," Management World, vol. 5, no. 5, pp. 145-146, 2004.

[35] E. L. Plambeck and L. Denend, "The greening of Wal-Mart's supply chain," Supply Chain Management Review, vol. 11, no. 5, pp. 18-25, 2007.

[36] M. Laroche, J. Bergeron, and G. Barbaro-Forleo, "Targeting consumers who are willing to pay more for environmentally friendly products," Journal of Consumer Marketing, vol. 18, no. 6, pp. 503-520, 2001.

[37] L. He, D. Zhao, and Y. Liu, "Dynamic game of supply chain coordination based on automatically perform contract," System Engineering Theory and Practice, vol. 31, no. 10, pp. 1864-1878, 2011.

[38] A. Rubinstein, "Perfect equilibrium in a bargaining model," Econometrica, vol. 50, no. 1, pp. 97-109, 1982. 


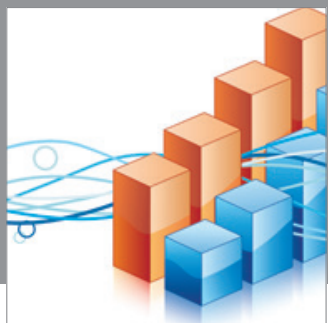

Advances in

Operations Research

mansans

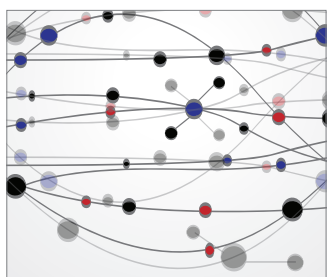

The Scientific World Journal
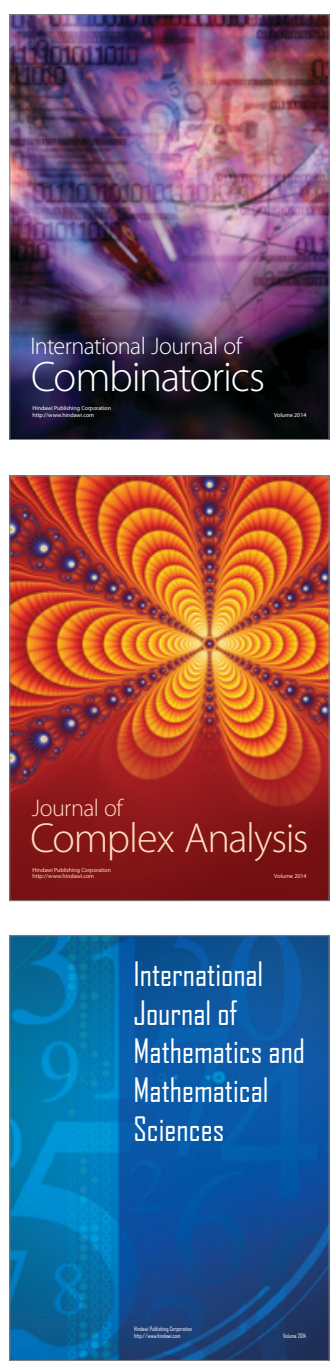
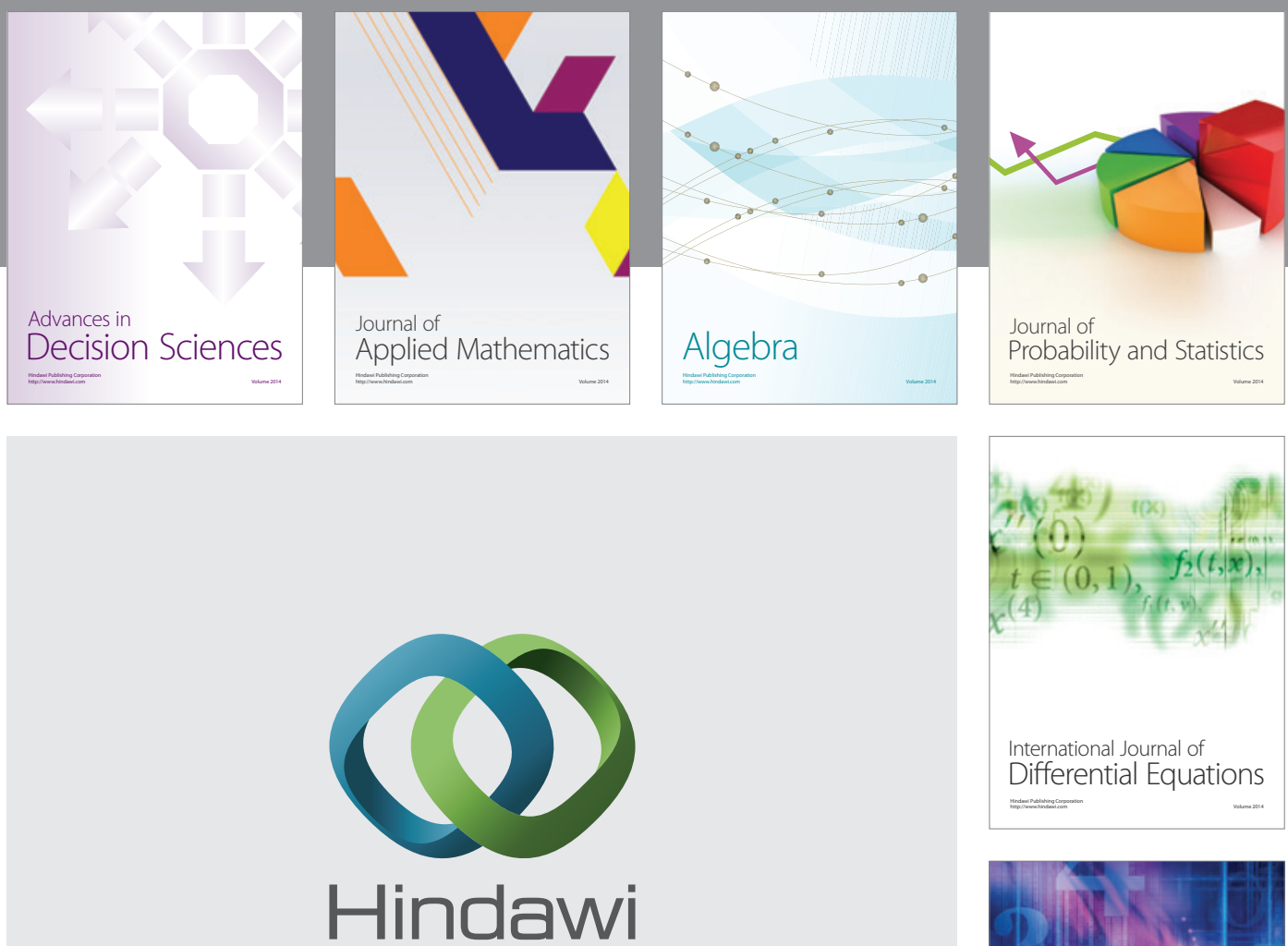

Submit your manuscripts at http://www.hindawi.com
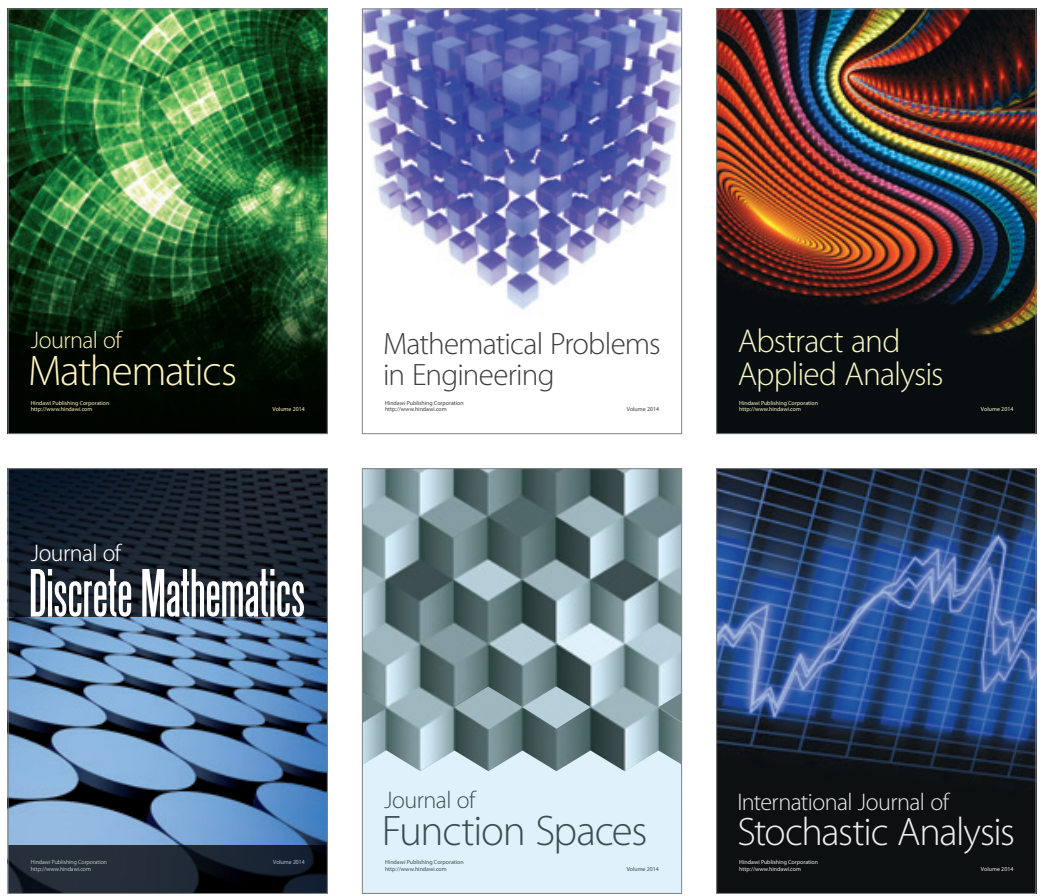

Journal of

Function Spaces

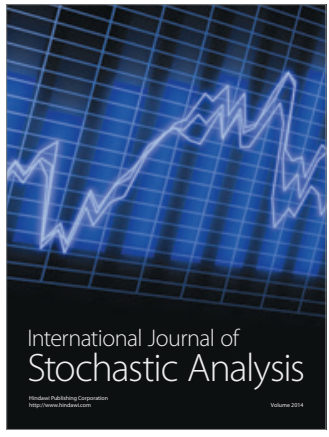

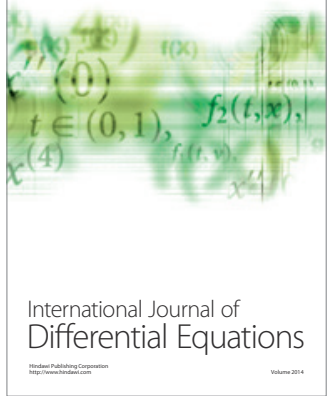
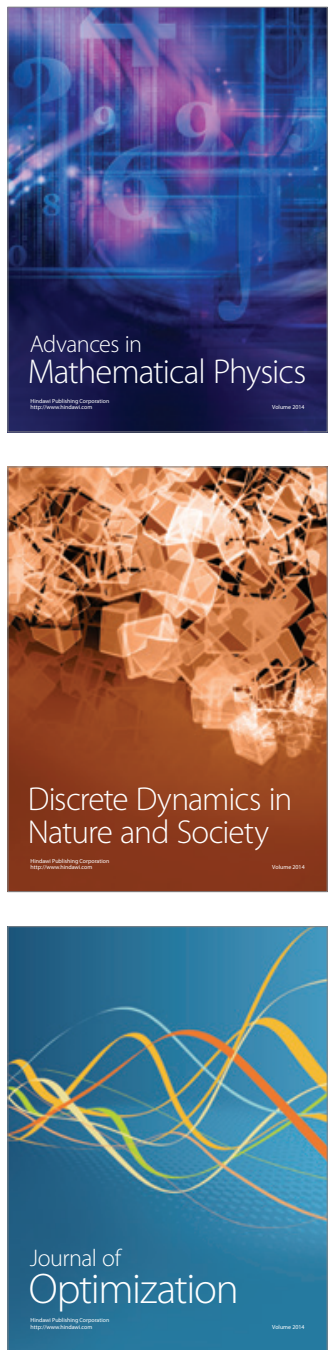